\title{
Lagu Dolanan dalam Permainan Tradisional sebagai Strategi Inovasi Pendidikan Sendratasik
}

\author{
Triyono Bramantyo ${ }^{1}$ dan Winarjo Sigro Tjaroko
}

Prodi Pendidikan Musik, Fakultas Seni Pertunjukan, Institut Seni Indonesia Yogyakarta

\begin{abstract}
Dolanan songs in traditional games as an innovation strategy for the art education of drama, dance, and music. This research focuses on constructing alternative learning in an innovation strategy of art education of drama, dance, and music through dolanan songs in traditional children's games. Alternative strategies are needed in providing diversification of learning because the problem that occurs in the art education of drama, dance, and music is the existence of cultural conflicts that impact the stagnation of the learning model. The choice of the dolanan song is due to its meaning and philosophy, which have aesthetic value in aspects of motion, drama, and music with the ability to adapt to the dynamics of science and technology. A library method is an approach used to construct an innovation strategy from the meaning contained in the text of children's traditional game songs. They implicitly have imaginative factors, particular messages, and aesthetic elements. Therefore, they can be relevant to the social conditions of society in the new cultural order. Based on the elaboration done in the study, three strategies are found which can answer the research problems, and are used in developing the art education of drama, dance, and music. They are as follows: firstly, the strategy of revitalizing the dolanan song in traditional children's games; secondly, the art education of drama, dance, and music is an appreciation education about aesthetic meaning; and thirdly, the formal transmission strategy of traditional transmission children's games through schools.
\end{abstract}

Keywords: dolanan song; traditional game; innovation strategy; education; the art education of drama, dance, and music

\begin{abstract}
ABSTRAK
Penelitian ini mempunyai fokus untuk mengkontruksi alternatif pembelajaran berupa strategi inovasi pendidikan sendratasik melalui lagu dolanan pada permainan tradisional Anak-anak. Alternatif strrategi diperlukan dalam memberikan diversifikasi pembelajaran, karena permasalahan yang terjadi pada pendidikan sendratasik adalah adanya konflik kultural yang memberikan dampak terhadap stagnanisasi model pembelajaran. Pemilihan lagu dolanan dikarenakan karakteristik makna dan filosofinya mempunyai nilai estetik pada aspek gerak, drama dan musik dengan kemampuan adaptasi mengikuti dinamika ilmu pengetahuan dan teknologi. Metode kepustakaan merupakan pendekatan yang digunakan untuk mengkontruksi strategi inovasi dari pemaknaan yang terkandung di dalam teks lagu-lagu permainan tradisional anak-anak yang secara implisit memiliki faktor imajinatif, pesan-pesan khusus, dan unsur estetis di dalamnya sehingga relevan dengan kondisi sosial dari masyarakat pada tatanan kebudayaan baru. Berdasarkan elaborasi yang dilakukan, ditemukan tiga buah strategi yang bisa menjawab permasalahan tersebut di atas serta digunakan dalam mengembangkan pendidikan Sendratasik. Pertama strategi revitalisasi lagu dolanan pada permainan tradisional anak-anak, kedua strategi pendidikan Sendratasik sebagai pendidikan apresiasi tentang makna estetik, dan ketiga, strategi transmisi formal permainan tradisional anak-anak melalui sekolah.
\end{abstract}

Kata kunci: lagu dolanan; permainan tradisional; strategi inovasi; pendidikan; sendratasik

Alamat korespondensi: Prodi Pendidikan Musik, Fakultas Seni Pertunjukan, Institut Seni Indonesia Yogyakarta, Jalan Parangtritis Km. 6.5 Yogyakarta. E-mail: bramantyo.triyono@gmail.com; HP.: 08995045678. 


\section{Pendahuluan}

Seni drama, tari dan musik merupakan sebuah ruang pendidikan yang dirancang untuk mengakomodasi kebutuhan pasar, industri mengenai tenaga pendidik untuk tingkat sekolah menengah pertama dan atas, sehingga kurang memperhatikan model yang sesuai untuk anakanak, khususnya anak usia dini padahal berdasarkan kurikulum pendidikan anak usia dini dijelaskan bahwa salah satu bidang pengembangan yang diberikan adalah seni. Fenomena yang terjadi di lingkungan pendidikan seni untuk anak-anak adalah ketiadaan tenaga pendidik yang mempunyai kualifikasi untuk memberikan pembelajaran drama, tari dan musik, biasanya Lembaga pendidikan memposisikan seni sebagai salah satu muatan lokal atau ekstrakuliler sehingga memerlukan tenaga pendidik dari luar dampaknya cost yang dikeluarkan peserta didik juga akan meningkat.

Pendidikan seni untuk anak-anak merupakan salah satu unsur dari enam bidang pengembangan yang di desain secara holistik integratif dengan tujuan memberikan peluang bermain seni dan pengalaman estetik. Lima bidang pengembangan untuk anak-anak berdasarkan visi generasi emas selain seni adalah kognitif, fisik motorik, nilai agama moral, bahasa dan sosial emosional. Sebagai salah satu bidang pengembangan, seni secara dimensi waktu mempunyai waktu yang lebih singkat, tetapi apabila pemilihan muatan materi tepat dan sesuai maka nilai estetik sering menjadi landasan mengembangkan kecerdasan sosial emosional, bahasa, nilai agama dan moral bagi tumbuh-kembang anak, seperti permainan tradisional.

Upaya memposisikan permainan tradisional pada dalam pengembangan psikofisologis pendidikan bukan ranah romantisme tetapi lebih pada tahapan pendokumentasian, pengadaan transkripsi, transmisi, serta re-diseminasi permainan tradisional anak-anak karena khasanah permainan tradisional terdapat elemen-elemen dramatik, densikal atau tari dan sekaligus musikal. Lagu dolanan anak yang ada di Jawa misalnya bisa dijadikan model pembelajaran (Raharja, 2021). Elemen yang mempunyai peran penting untuk mengkontruksi sebuah makna pesan adalah musikal, misalkan dalam permainan Jamuran, Cublak-Cublak Suweng, Suklu-suklu Batok, Padhang Bulan dimana kekuatan pada permainan secara audio visual akan lebih jelas pemaknaannya apabila elemen musikal hadir pada permainan tersebut, yang dimaksud dengan lagu dolanan.

Nilai guna lagu dolanan di era modernisasi dan industri 5.0 sering mengalami transformasi lirik yang telah digubah ataupun intramusikal seperti lagu dolanan yang di olah dalam electronic digital music (EDM), disesuaikan dengan kebutuhan sehingga tanpa disadari menggerus nilai-nilai tradisi, padahal nilai-nilai tersebut telah terbukti mampu memberi karakter pada kepribadian dan identitas. Selain arus modernitas, perubahan terhadap konsumsi lagu dolanan secara implisit dan eksplisit dipengaruhi oleh kekeliruan konsep transmisi, terbukti munculnya adalah lagu pop anak-anak yang cenderung dinyanyikan sendirian dan kurang makna yang jelas dari aspek syairnya. Anak-anak semakin individualistis dan kurang diperkenalkan pada lingkungan alam dan sosial. Modernisasi bersifat dualisme. sehingga melahirkan berbagai konflik, salah satu di antaranya adalah konflik kultural. Clifford Geertz menyebut fenomena konflik kultural ini sebagai an incongruity of meaning (ketidaksesuaian makna) dengan implikasi bahwa hal itu merupakan sifatsifat makna itu sendiri. (Geertz, 1992: 196).

Perubahan nilai guna lagu dolanan dalam era 5.0 selain menimbulkan konflik kultural juga menggerus konsep ekstramusikal seperti pembelajaran tentang nilai-nilai kebersamaan, kegotong-royongan, kerukunan, dan keguyuban yang menjadi wilayah ambivalensi. Pro kontra berupa penilaian bahwa nilai-nilai itu sedang bergeser disebabkan oleh percepatan proses modernisasi yang ternyata imbalans dengan proses perubahan kebudayaan kita, maka yang terjadi adalah ketidaksiapan dalam mengelola perubahan keadaan itu, salah satunya adalah lembaga pendidikan sebagai salah satu mediator dan fasilitator serta dinamisator ke arah perubahan yakni sebagai the agent of cultural change.

Permasalahan konflik kultural yang dihasilkan dari perubahan nilai guna lagu dolanan sekarang 
ini terjadi pada lembaga pendidikan baik formal ataupun non formal, seperti stagnanisasi pengembangan kurikulum pendidikan sendratasik, sebagai contoh adalah transmisi program-program pengajaran yang dilaksanakan belum berorientasi pada hakakat nilai tetapi masih menunjukkan pendidikan di Indonesia mengenai persoalan pendidikan manusia Indonesia seutuhnya yang belum ada ukuran dan belum jelas wujudnya. Persoalan ini memberikan indikasi bahwa pembelajaran tidak berupaya manahan laju disintegrasi kultural dan belum optimalnya strategi merencanakan sesuatu untuk menghadapi konflik kultural sehingganya menimbulkan rasa khawatiran dalam menghadapi sublimasi inversi kultural. Permasalahan mengenai belum optimalnya strategi inovasi dalam pendidikan sendratasik tersebut yang menuntut, menuntun untuk mengambil tindakaan rasional jangka panjang. Selain itu, arus informasi yang tengah bergerak dengan ukuran mega speed, modernisasi negara-negara berkembang yang seolah berpacu dengan hari esok demi mengejar keterbelakangan, sebaliknya, perkembangan sains dan teknologi yang seolah tak terkejar lagi oleh negara berkembang, adalah realita kekinian yang meresahkan. Wujud globalisasi mendesak budaya lokal dan budaya nasional suatu bangsa. Semua itu adalah fenomena masa kini yang membawa konsekuensi logis degradasinya nilai-nilai tradisional yang semakin lama dipersepsikan sebelah mata dan bahkan hampir dilupakan. Kasus nilai guna lagu dolanan dalam strategi inovasi telah diuraikan, salah satunya adalah Bräuchler yang memberi contoh bagaimana tradisi pela dan gandong telah berhasil membawa kedamaian kembali di Ambon yang sebelumnya mengalami konflik sosial. Bayangkan jika tradisi pela dan gandong sudah dilupakan, bisa jadi konflik sosial tersebut berkepanjangan tanpa terjadinya rekonsiliasi. (Horstmann, 2013: 21). Tidak kurang dari Alfin Toffler, seorang sosiolog Amerika, telah jauh-jauh hari mengingatkan "We are creating a new society. Not a changed society. Not an extended, larger-than-life version of our present society. But a new Society. This simple premise has not yet begun to tincture our consciousness. Yet unless we understand this, we shall destroy ourselves in trying to cope with tomorrow. (Toffler, 1971: 172).
Kekhawatiran terhadap perubahan nilai guna lagu dolanan dalam permainan tradisional anak-anak sering menjadi sebuah upaya untuk menghindar dari persoalan-persoalan, dengan penggunaan istilah transformasi budaya yang mempunyai bahasa lebih halus dan tidak se-ekstrim bahwa kita tengah menghancurkan diri kita sendiri dalam beradaptasi dengan hari perkembangan jaman, teknologi serta inovasi pendidikan. Konsep transformasi budaya secara umum dijelaskan oleh Mardiman bahwa transformasi budaya adalah perubahan-konsep, bentuk, fungsi, dan sifatbudaya untuk menyesuaikan dengan konstelasi dunia," (Mardiman, 1994: 15). Dengan demikian istilah transformasi budaya itu seolah mengandung rencana, sasaran, dan tujuan-tujuan di dalamnya. Secara sederhana Johanes Mardiman melemparkan premisnya sebagai berikut:

"Setelah memahami kondisi masyarakat kita sekarang dan dapat menemukan rumusan masyarakat modern yang kita inginkan, kita perlu menentukan langkahlangkah untuk mencapainya. Sistem nilai, pola pikir, tingkah laku dan adat kebiasaan yang selama ini berlaku, tetapi sudah usang atau bahkan menjadi kendala bagi kemajuan yang dituntut untuk menunjang pembangunan, dapat kita pertanyakan relevansinya." (Mardiman, 1994: 16).

Konsep pembangunan bukan interpretasi tunggal seolah hanya ada pada pihak penguasa, tetapi setiap elemen bangsa harus turut serta dalam ruang untuk mencapai tujuan bersama, salah satu tujuan pembangunan adalah mencerdasarkan kehidupan bangsa, maka salah upaya yang harus dilakukan adalah beradaptasi dengan perkembangan jaman tanpa menghilangkan nilainilai lokal jenius bukan hanya sekedar mengubah lagu dolanan menjadi komoditi ekonomi sehingga disadari atau tidak, mengemas lagu dolanan dalam permainan tradisional anak-anak yang semata-mata hanya demi mengejar peningkatan devisa melalui turisme atau dengan istilah "wisata budaya" itu, tidak lain adalah penghancuran atas nilai-nilai tradisional itu sendiri. Dengan tepat George Junus Aditjondro, sebagaimana dikutip oleh Mardiman, memberi gambaran kepada kita seperti berikut ini: 
"... Hasil interaksi antara sistem budaya hotel internasional itu dengan kebudayaan dan alam setempat yang menjadi "jualan" dalam industri pariwisata, melahirkan suatu sistem budaya baru, suatu sistem budaya blasteran yang tidak sungguh-sungguh berakar dalam sistem budaya asli yang melahirkannya, dan lebih bersifat suatu budaya pajangan (etalase).” (Mardiman, 1994: 129).

Komparasi eksistensi lagu dolanan dalam permainan tradisional sekarang ini keberadaannya cukup tragis, beberapa kasus adalah di Inggris anakanak masih mendengar nyanyian seperti "London bridge is going down, going down, going down ..., di Amerika anak-anak masih bermain "Peek a boo..." sambil menyanyikannya, di Minang mungkin kita tidak pernah lagi melihat anak-anak bermain "Jamuran" atau permainan tradisional lainnya. Budaya populer yang "menyerang" (karena sifatnya yang agresif) dengan hebatnya melalui media elektronik seperti televisi dan industri musik dan aplikasi musik, juga "menjejalkan" ke telinga anakanak lagu-lagu pop anak yang, meski menembus masyarakat, tetapi belum tentu memiliki nilai-nilai edukatif dan bahkan mungkin tidak menawarkan apresiasi estetis sama sekali. Mereka tidak akan pernah lagi tersentuh pengalaman estetis yang sangat penting bagi perkembangan intelegensi mereka. Arti pentingnya faktor imajinatif di dalam lagu-lagu permainan tradisional dengan mengutip pendapat Polanyi, dapat digambarkan “... Thus, works of science, engineering, and the arts are all achieved by the imagination. ... But we do have to achieve an imaginative vision to "use "a work of art, that is, to understand and enjoy it aesthetically." (Polanyi and Prosch, 1977: 85).

\section{Metode Penelitian}

Permasalahan konflik kultural yang disebabkan degradasi implementasi nilai guna lagu dolanan dalam permainan tradisional pada pendidikan seni drama tari dan musik merupakan kasus yang menarik ditelaah dalam berbagai perspektif. Sebagai sebuah musik vokal yang bukan hanya menjadi subyek atau iringan dalam permainan tradisional seperti Jamuran; Suklu-Suklu Batok dan Cublak-Cublak Suweng, lagu dolanan secara faktual sering dijadikan kajian-kajian dalam berbagai perspektif memberikan sebuah ruang untuk memaknai nilai-nilainya sebagai suatu strategi. Berdasarkan hal tersebut metode penelitian mempergunakan metode kualitatif, strategi studi kepustakaan. Pemilihan metode penelitian kepustakaan karena terdapat beberapa alasan yang mendasarinya. Pertama bahwa sumber data primer dalam penelitian ini bersumber dari jurnal, buku perpustakaan atau dokumen-dokumen lain dalam bentuk tulisan maupun literatur yang lain. Kedua, studi kepustakaan diperlukan sebagai salah satu cara untuk memahami gejala-gejala baru yang terjadi yang belum dapat dipahami, kemudian dengan studi kepustakaan ini akan dapat dipahami gejala tersebut.

Adapun tahap-tahap yang dilakukan penulis dalam penelitian kepustakaan adalah mengumpulkan bahan-bahan penelitian. Karena dalam penelitian ini adalah penelitian kepustakaan, maka bahan yang dikumpulkan adalah berupa informasi atau data empirik yang bersumber dari buku-buku, jurnal, hasil laporan penelitian resmi maupun ilmiah dan literatur lain yang mendukung tema penelitian ini. Tulisan-tulisan mengenai lagu dolanan pada permainan tradisional dipilih berdasarkan kesamaan antara nama lagu dengan nama permainan tradisional, sehingga memperoleh Jamuran, Suklusuklu Batok dan Cublak Cublak Suweng.

Membaca bahan kepustakaan yaitu domain membaca dalam ruang lingkup yang besar bukan sekedar membaca tulisan, tetapi juga mengobservasi fenomena-fenomena mengenai lagu dolanan pada permainan tradisional. Pembacaan ulang dilakukan dalam wilayah etnografi virtual yaitu konten di media sosial yang mengunggah lagu dolanan baik dalam format asli, ataupun gubahan. Selanjutnya membuat catatan penelitian, pada proses ini peneliti membuat sebuah log book yang berisi catatan-catatan dari proses pembacaan baik yang tertulis mengenai pemanfaatan lagu dolanan pada permaianan tradisional sebagai model inovasi Pendidikan ataupun fenomena visual lagu cublakcublak suweng, suklu-suklu batok dan jamuran dalam konten audio visual 
Mengolah catatan penelitian. Semua bahan yang telah dibaca kemudian diolah atau dianalisis untuk mendapatkan suatu kesimpulan yang disusun dalam bentuk laporan penelitian. Penelitian ini tergolong dalam jenis penelitian pustaka (library research) karena dalam penelitian ini, peneliti menelaah tentang konsep pendidikan berbasis pengalaman. Teknik Analisis Data Teknik analisis data yang penulis gunakan diantaranya adalah Analisis Konten yang memanfaatkan seperangkat prosedur untuk menarik kesimpulan yang sahih dari sebuah buku atau dokumen ke dalam 6 tahapan, yaitu: a. Unitizing; b. Sampling; c. Recording/coding (perekaman/koding); d. Reducing (pengurangan) data atau penyederhanaan data; e. Abductively inferring (pengambilan simpulan), bersandar kepada analisa konstuk dengan berdasar pada konteks yang dipilih; dan f. Naratting (penarasian) atas jawaban dari pertanyaaan penelitian.

\section{Hasil dan Pembahasan}

Lagu dolanan dalam permainan tradisional secara imajinatif, esensinya merupakan refleksi dari drama, tari dan musik, sehingga sudah selayaknya terdapat sebuah ruang dalam muatan pengajaran di pendidikan sendratasik yang mengakomodasi hakikat lagu dolanan. Sebagai suatu obyek yang mempunyai nilai-nilai filosofi, lagu dolanan mempunyai dua faktor yang sering dilupakan, menjadi ketaksadaran komunal yaitu popularisme dan komersialisme. Kedua faktor tersebut yang akhirnya menjadi eksplorasi habitus, modal dalam perubahan nilai gunanya dalam aktifitas masyarakat padahal apabila terdapat pemahaman terhadap nilai-nilai lokal jenius yang terdapat di dalamnya maka terdapat peluang besar untuk menjadikannya salah satu obyek strategi inovasi pembelajaran pada Pendidikan, khususnya Pendidikan sendratasik, terdapat 3 strategi inovasi.

\section{Strategi Ravitalisasi Permainan Tradisional Anak-anak}

Strategi pertama yaitu revitalisasi permainan tradisional anak-anak ini bukan dalam konteks bernostalgia semata-mata, pendokumentasian, termasuk pengadaan transkripsi, transmisi, serta re-diseminasi permainan tradisional anak-anak dirasa perlu diadakan, karena kita semua paham bahwa di dalam khasanah permainan tradisional kita terdapat elemen-elemen dramatik, densikal (tari) dan sekaligus musikal. Inilah startegi pertama, yakni untuk revitalisasi seni permainan tradisional anak-anak demi pengembangan Pendidikan Sendratasik kita. Bila proyek pendokumentasian dan pengadaan transkripsi semacam itu sudah bisa dilaksanakan, maka lembaga pendidikan formal maupun non-formal sebagai agen perubahan budaya, selanjutnya mentransmisikannya melalui program-program pengajaran yang dijalankannya, Jepang misalnya, butuh waktu bertahun-tahun untuk menahan laju perubahan budaya yang ekstrim dengan cara menggali dan menghidupkan kembali nilai-nilai tradisi mereka dalam berbagai elemen keseharian mereka, Kuil-kuil yang kuno direnovasi dengan biaya yang sangat tinggi dan memakan waktu lama karena meliputi aset kuilkuil kuno di seantero Jepang. Kesenian tradisional diberi insentif dan didorong untuk dikembangkan secara modern meski tanpa menghilangkan nilainilai tradisionalnya.

Permainan anak-anak tradisional didokumentasikan, ditranskrip ulang, dan direkam serta disebarkan ke seluruh sekolah. Tidak hanya itu, setiap tahun mereka mengadakan festival genre (jenis lagu) tersebut mulai tingkat lokal sampai nasional. Tradisi membawa anak-anak usia 3, 5 dan 7 tahun (sichigosan) ke kuil untuk diberkahi adalah salah satu bentuk dari pelestarian budaya tradisional mereka juga. Banyak contoh lagi yang bisa dipelajari dari Jepang dalam usahanya menahan laju perubahan budaya yang ekstrim dan yang cenderung "membelatarakan" manusia ke alam yang serba virtual dalam abad mega modern ini. Istilah revitalisasi jika diartikan secara luas, yakni adalah sebuah konsep yang diadaptasi dan secara praktis berarti reaplikasi elemen budaya lokal demi untuk membawa arah perubahan sesuai yang seharusnya kita kehendaki. Dari pengertian tersebut kita memahami bahwa masyarakat ingin membina sebuah keberlangsungan nilai-nilai dan menghindari sedapat mungkin perubahan- 
perubahan ekstrim yang mengganggu tata-nilai kebersamaan yang harmonis. Tentu juga harus kita sadari bahwa kebanyakan masyarakat yang menghendaki revitalisasi memahami pula bahwa tidak mungkin berharap dan menginginkan terciptanya kembali kondisi masa lalu yang sama persis, karena hal demikian itu berarti menolak kemajuan. Revitalisasi lagu dolanan dalam permainan tradisional anak-anak memberikan sebuah pemaknaan.

\section{Strategi Apresiasi Estetik Permainan Tradisional Anak-anak}

Strategi ke dua adalah membuat dan merumuskan teori-teori demi pengembangan teori dan analisis lagu-lagu permainan tradisional kita yang selama ini cenderung 'dibiarkan' karena ketiadaan ilmu teoretis untuk menganalisisnya. Diabaikannya repertoar permainan tradisional anak-anak kita nampak sekali menonjol, meski tidak perlu dijelaskan secara rinci. Musikologi Indonesia, sebutlah etnomusikologi Indonesia, sejauh ini merupakan disiplin yang diimpor dari Barat yang mengandalkan nilai-nilai "obyektif, universal, serta bebas nilai", sambil meremehkan nilai-nilai "transubyektif, historikal, serta kaya nilai" seperti esensi yang terdapat di dalam repertoar permainan tradisonal anak-anak. Dengan istilah transubyektif penulis maksudkan adalah hubungan yang dialogis antar manusia, seperti ketika secara teatrikal anak-anak bermain "Jamuran," misalnya.

Pengertian historikal adalah bahwa kita memiliki sejarah panjang hingga menjadi diri kita, menjadi negara kita yang seperti sekarang ini. Dimensi kesejarahan ini dapat diajarkan melalui permainan tradisional anak-anak kita. Kaya nilai, seperti misalnya lagu-lagu pastoral yang kita miliki, di mana permujaan keindahan alam, bersatu dengan alam, mengenal alam secara lebih dekat, kebersamaan, kegotong-royongan, kerukunan, dan keguyuban dibina kembali dengan cara yang lebih modern untuk menghindari kesan alergi atau penolakan terhadap nilai-nilai yang tradisional, primitif, dan dianggap kuno.

Esensi yang sesungguhnya dari pembelajaran Sendratasik adalah agar para peserta didik memperoleh peluang untuk bermain Sendratasik yang terbaik, sekaligus juga demi agar mereka memperoleh pula pengalaman estetik Sendratasik yang terbaik. Dalam konteks ini kita meletakkan konsep Pendidikan Sendratasik yang berpusat kepada peserta didik (student-centered learning). Pendidikan Sendratasik merupakan disiplin yang berhubungan dengan estetika, daya perseptif, kreatif serta memiliki dimensi-dimensi intelektual. Sebab itu pendidikan Sendratasik memiliki peran dalam membentuk pengembangan kemampuan kreatif, proses berpikir intuitif, dan penajaman responrespon emosional yang penting bagi ketajaman kecerdasan emosional (emotional intelligent). (Benham, 2011: 18).

Perlu dicatat bahwa pentingnya pengalaman estetik sudah menjadi diskursus filsafat klasik. Kontribusi-kontribusi saintifik yang disampaikan oleh Kant, Kierkegaard, Husserl, Heidegger, Dewey dan Peirce (dan lain-lain), semuanya sudah menawarkan kepada kita tentang definisi-definisi serta tanggapan-tanggapan atas nilai (estetik) yang membawa kehidupan kita lebih bermakna. (Turner, 2017: 17).

Secara implisit uraian sebelumnya menggambarkan keprihatinan penulis atas pelaksanaan pengajaran dan pendidikan Sendratasik di sekolahsekolah kita selama ini. Materi pengajaran dan pendidikan seringkali mengabaikan seni tradisional dan kesenian rakyat kita, serta tak lebih dari sekedar pengenalan musik Barat dan kurang memperhatikan aspek penanaman pengalaman estetik yang justru merupakan esensi dari pengajaran dan pendidikan Sendratasik itu sendiri. (Bramantyo, 1999: 160).

\section{Strategi Transmisi Formal Permainan Tradisional Anak-anak}

Permainan tradisional anak-anak adalah salah satu bentuk tradisi lisan yang ditransmisikan dari generasi ke generasi secara oral, oleh karena itu tidak jelas sejak kapan genre ini mulai dikenal secara luas.Transmisi dalam suatu musik non literate misalnya musik dalam konteks ritual terdiri dari tiga aspek yaitu pelaku, konten, dan mekanisme (Irawati, 2016; 2019), demikian pula halnya dengan konteks ruang pembelajaran kelas musik 
di Pendidikan formal pentingnya menghadirkan tentang gambaran kehidupan masyarakat pengguna dalam keseharian terkait dengan music yang akan diajarkan (Irawati, 2021). Perlu kiranya ada strategi khusus terkait transmisi lagu-lagu dolanan anak dalam permainan tradisional ke ranah pendidikan formal.

Strategi ke tiga yang hendak ditawarkan di sini adalah proses transmisi lagu-lagu permainan tradisional yang terbukti secara musikal dan edukasional memiliki makna yang dalam. Dimaksud dengan proses transmisi dalam pengertian ini adalah proses pewarisan genre itu kepada anak-anak masa kini, yakni masa yang disebut krusial karena memasuki milenium ketiga yang sarat dengan bahaya, misalnya terputusnya hubungan generasi muda dengan tradisinya sendiri. Termasuk juga kekhawatiran yang diwujudkan dalam pertanyaanpertanyaan yang sudah disebutkan di atas tadi.

Perlu ditegaskan di sini bahwa seni drama, tari dan musik dalam pendidikan — penulis menyebutnya dengan istilah "Sendratasik pendidikan"- memiliki efek katartik yang mengekspresikan beberapa kebenaran psikologis yang dalam. Misalnya, dapat dipahami bahwa transmisi budaya bukan hanya soal pewarisan katakata, yakni makna kata-kata yang kita kenal dalam bahasa beserta rekognisi (pengenalan kembali) bahasa demi ekspresi-ekspresi tertentu. Efek katartik yang dimaksud adalah lebih dari itu, yakni nilai-nilai pewarisan budaya disertai pemahaman berbasis struktur logika (logical-structural) dan pemahaman berbasis metaforika intuitif (intuitivemetaphorical).

Efek katartik adalah sebuah kondisi tercapainya pengalaman seni (estetika seni). Demikianlah pendidikan Sendratasik seharusnya diarahkan. Efek katartik adalah salah satu bentuk kedalaman dari kebenaran psikologis yang merupakan manfaat dari pendidikan (seni). Istilah katartik secara harafiah berarti membersihkan perut.

Efek katartik ini juga dapat dijumpai dalam genre yang sedang dibahas ini. Ketika modernisme yang diboncengi oleh individualisme sudah sedemikian bahayanya, maka kerinduan pada genre ini bukan lagi semata-mata ungkapan nostalgik belaka, melainkan lebih merupakan himbauan dan ajakan atau katakanlah seruan, untuk kembali kepada jati diri yang sesungguhnya tidak memiliki dasar-dasar budaya individualistis.

Wacana lagu-lagu anak-anak dewasa ini diakui atau tidak lebih menonjolkan perhitungan mekanisme dan selera pasar yang "dipaksakan". Seolah kepada anak-anak tidak diberikan alternatif untuk meadengarkan musik dan nyanyian yang baik secara edukasional. Lirik atau syair lagu-lagu anak-anak sekarang ini lebih banyak bersifat mainmain dan kadang bahkan makna syair diabaikan sama sekali. Banyak contoh yang bisa disebutkan di sini hanya sekedar memberi gambaran tentang wacana lagu-lagu anak-anak masa kini.

Tidak sedikit orang mungkin lantas berkomentar secara naif, "apa boleh buat, jaman memang sudah berubah, dan kita tidak tahu ke mana arah perubahan itu." Siapa pun pasti setuju, bahwa kita memang menghendaki perubahan dalam arti kemajuan menuju kebahagiaan dan kesejahteraan manusia yang adil dan merata. Akan tetapi sudah barang tentu kita juga seharusnya setuju bahwa perubahan dan kemajuan itu harus memiliki basis nilai-nilai moral yang meski universal, namun juga membawa serta kaidah-kaidah jati diri yang berciri khas kebangsaan, yakni yang bersifat lokal dan nasional.

Ki Hadjar Dewantara sudah sejak semula mengingatkan arti penting trilogi (kontinyu, konvergen, dan konsentris) pendidikan nasional melalui doktrinnya yang terkenal itu, tetapi yang kini juga sudah hampir dilupakan banyak orang. Dunia pendidikan beberapa dekade belakangan ini hanya sebatas sebagai receiver dari istilah keren transfer of knowledge. Pendidikan kita belum menampakkan diri sebagai agent of change meski slogan ini sering didengungkan oleh para pemimpin bangsa ini.

Iklim berkesenian tradisional serius yang lebih menitikberatkan artistik adiluhung, termasuk pengembangan genre-genre dalam arti yang luas, misalnya sampai yang bernuansa contemporary sekalipun, harus mulai dipikirkan sejak sekarang. Nostalgia terhadap masa lalu —masa ketika lagu-lagu permainan tradisional terasa demikian menghibur dan mendidik kita untuk arif dan jujur terhadap sesama, terhadap orang tua atau 
yang dituakan, terhadap lingkungan alam, dan sebagainya - sangat masuk akal dan bukan sekedar eskapisme atau sekedar back to basic terhadap nilainilai tradisional.

Permainan tradisional anak-anak memiliki nilai-nilai yang lebih dramatik, densikal, dan musikal, sekaligus memiliki nilai-nilai pendidikan moral dan nilai-nilai kesopanan budi pekerti yang sangat diperlukan bagi keutuhan bangsa ini. Anakanak harus dikembalikan pada dunia mereka yang penuh keceriaan yang sesungguhnya, bukan yang virtual atau yang semu-semu saja. Anak-anak harus diberi tempat untuk bermain, sekolah harus memberi fasilitas tempat bermain untuk anak-anak. Permainan tradisional anak-anak harus dihidupkan kembali, dan diajarkan di sekolah-sekolah. Pemerintah daerah harus menyediakan sebidang tanah di setiap sudut kampung tempat tinggal mereka berupa taman-taman untuk bermain. Taman-taman itu diberi fasilitas untuk anak-anak disertai dengan pemikiran safety first dan cleaning service yang memadai layaknya negara maju.

Jika selama ini kita cukup disibukkan dengan masalah-masalah ekonomi dan politik disertai isuisu yang jauh dari mementingkan kepentingan anak-anak generasi penerus republik ini, maka kini saatnya kita merenungkan hal itu. Anakanak harus diberi prioritas dengan pemikiran yang komprehensif sehingga kelak kita tidak akan kehilangan identitas kebangsaan kita.

\section{Kesimpulan}

Lagu dolanan dalam permainan tradisional anak-anak merupakan sebuah obyek yang mampu menjadi agent perubahan dalam mengembangkan strategei inovasi pendidikan sendratasik. Garap estetik pada lagu Jamuran, Cublak-Cublak Suweng dan Suklu-suklu Batok merupakan dualitas yang mempunyai nilai garap estetik dalam pengembangan pendidikan sendratasik dan pengembangan pendidikan moral, sehingga elaborasi nilai-nilai ditemukan tiga buah strategi yang bisa menjawab permasalahan tersebut di atas serta digunakan dalam mengembangkan pendidikan Sendratasik. Pertama strategi revitalisasi lagu dolanan pada permainan tradisional anak-anak, kedua strategi pendidikan
Sendratasik sebagai pendidikan apresiasi tentang makna estetik, dan ketiga, strategi transmisi formal permainan tradisional anak-anak melalui sekolah.

\section{Kepustakaan}

Aditjondro, George Junus. (1994). "Menghadap Dampak Negatif Pariwisata di Bidani lingkungan Hidup," dalam Johanes Mardimai (Ed.), Jangan Tangisi Tradisi: Transforms Budaya Menuju Masyarakat Indonesia Ma em. Yogyakarta: Kanisius.

Benham, John L (2011). Music Advocacy Moving from Survival to Vision. New York: Rowman \& Littlefield Publishers, Inc.

Bramantyo, Triyono. (1999). Makna dan Hakiki Karya Seni: Sebuah Tinjauan Estetis untuk Dasar-dasar Pendidikan Musik di Sekolah Umum, Jurnal Seni, BP-ISI Yogyakarta, 6 (1). Fletcher, Peter. (1987). Education \& Music. New York: Oxford University.

Geertz, Clifford. (1992). Tafsir Kebudayaan, Francisco Budi Hardiman (penerjemah). Yogyakarta: Kanisius.

Horstmann, Thomas RA (Ed.). (2013). Faith in the Future Understanding the Revitalization of Religions and Cultural Traditions in Asia. Leiden: Brill.

Irawati, Eli. Wisma Nugraha Ch. R, Timbul Haryono. (2016). Transmisi Kelentangan dalam Masyarakat Dayak Benuaq. Resital: Jurnal Seni Pertunjukan, 17 (1), 1-17. doi: https://doi.org/10.24821/resital.v17i1. 1686.

Irawati, Eli. (2019). Transmission of Kelentangan Music Among the Dayak Benuaq of East Kalimantan in Indonesia. Malaysian Journal of Music, 8 (1), 108-121. https://doi. org/10.37134/mjm.vol8.7.2019

Irawati, Eli. (2021). The Transmission of Resilience Learning in the Context of Formal Education an Ethnomusicological Review. Linguistics and Culture Review, 5 (S3), 1040-1053. https:// doi.org/10.21744/lingcure.v5nS3.1664

Jatman, Darmanto. (1999). Psikologi Jawa. Yogyakarta: Yayasan Bentang Budaya. Lubis, Mochtar. (1985). Transformasi Budaya untuk 
Masa Depan. Jakarta: Inti Idayu Press.

Mardiman, Johanes. (1994). "Kata Pengantar" Johanes Mardiman (Ed.), Jangan Tangi Tradisi: Transformasi Budaya Menu] Masyarakat Indonesia Modem. Yogyakarta: Kanisius.

Mistui, Izumi (Ed.). 2020). Cultural Translation of Management Philosophy in Asian Companies Its Emergence, Transmission, and Diffusion in the Global Era. Singapore: Springer Nature Singapore Pte Ltd.

Polanyi, Michael dan Prosch, Harry. (1979). Meaning. Chicago: The University of Chicago Press.
Popper, Karl R. (1989). Objective Knowledge: An Evolutionary Approach. Oxford, Clarendon Press.

Raharja, Budi. (2021). Tembang Anak Jawa Sebagai Media Pembelajaran Membaca. Resital: Jurnal Seni Pertunjukan, 22 (2), 80-88. doi: https:// doi.org/10.24821/resital.v22i2

Toffler, Alfin. (1971). Future Shock. London: Panbooks Ltd.

Turner, Phil. (2017). A Psychology of User Experience Involvement, Affect and Aesthetics. Switzerland: Springer International Publishing. 